\title{
Design of Photovoltaic-Thermal (PV/T) for Building Integrated Photovoltaic Systems
}

\author{
Syafaruddin, Satriani Latief, and Wahyu H. Piarah
}

\begin{abstract}
The increasing in output efficiency will be always very challenging to photovoltaic technology. One of the methods is to utilize the thermal energy arises in the back side of PV module, called photovoltaic-thermal (PV/T). The advantage of this system is the output of electricity and thermal energy can be obtained simultaneously. In addition, the electrical efficiency can be indirectly improved since the thermal system acts as cooling system. The research utilizes the microcontroller ATmega8535 to operate pump in order to flow water through designed spiral pipe once the threshold temperature inside the heat box extraction is reached, therefore high temperature water can be observed in the outlet pipe. Several testing scenarios under clear sky and cloudy sky conditions are conducted in order to confirm the performance of our proposed system.
\end{abstract}

Index Terms-Control circuit, hybrid photovoltaic-thermal, microcontroller, thermal sensor.

\section{INTRODUCTION}

The efficiency conversion of photovoltaic system can be increased by utilizing the thermal energy produced at the backside of the module. The high density of energy thermal can be observed at the back side of PV module is caused by resistivity material composing the PV module that is encapsulated by module frame and more intensify by the ambient temperature. The photovoltaic system with utilizing thermal energy is well-known as hybrid photovoltaic-thermal. At glance, the thermal system functions as radiator system, therefore the implementation of this system will make the electrical efficiency increases simultaneously due to the reduction of negative temperature-voltage coefficient effects.

Research and development of hybrid photovoltaic-thermal technology has been investigated since 1970 with significant improvement in innovation of manufacturing products [1]. The significant outputs are new theory come up with field testing including identification of several important parameters. The design and experimental thermal photovoltaic for the building exterior applications have been attracted much attention since the last decade. The development is focused on the thermal extraction method through air circulation between photovoltaic cell and thermal

Manuscript received March 21, 2016; revised May 27, 2016.

Syafaruddin is with the Department of Electrical Engineering, Universitas Hasanuddin, Jl. Perintis Kemerdekaan Km.10 Tamalanrea, Makassar 90245, Indonesia (e-mail: syafaruddin@unhas.ac.id).

Satriani Latief is with the Department of Architecture, Universitas Bosowa Makassar, Jalan Urip Sumoharjo Km. 4, Makassar 90231, Indonesia (e-mail: satrianilatief@yahoo.com).

Wahyu H. Piarah is with the Department of Mechanical Engineering, Universitas Hasanuddin, Jl. Perintis Kemerdekaan Km.10 Tamalanrea, Makassar 90245, Indonesia (e-mail: wahyupiarah@yahoo.com). insulation of building exterior [2]. In this research, the simultaneous capability of power generation and thermal extraction during winter was the priority investigation. Some researchers are concentrated on the exergy analysis or the maximum capability of system to produce energy according to the thermodynamic process. The thermodynamic efficiency and exergy system efficiency have been recorded for region in India to about $55-65 \%$ and $12-15 \%$, respectively; where these values are very close to the predicted efficiency performed by other researchers in Denmark [3]. For more detailed energy and exergy analysis with constant air quantity has been investigated for micro scale hybrid photovoltaic thermal under frame design and climate parameters in India [4]. The calculation results showed that the thermal energy and exergy level can be increased to about $70 \%$ and $60 \%$, respectively.

The building integrated PV system approach is the most rational concept to increase the performance of photovoltaic systems. In fact, the BIPV system does not only improve the system efficiency regarding to electricity and thermal output simultaneously, rather to improve the thermal insulation of building structure [5]. The computer simulation was utilized to analyze the dependency between solar cell packages, velocity of fluid and electricity efficiency; the simulation results shown that there will be an optimal fluid flow to guarantee the high integration of performance in energy output. The research then continued to study the system sensitivity for water heating system with natural circulation using photovoltaic module of single crystalline Silicon [6]. The simulation and field experimental works were performed by considering several factors, such as air mass, solar cell packages and light transmission on the module absorber in order to obtain better performance of integrated PV-thermal system. Indeed, the computer simulation of hybrid photovoltaic system using Matlab/Simulink becomes more interesting to find the best strategic model for thermodynamic process that represents the hybrid photovoltaic-thermal system [7]. The simulation results revealed that computer Matlab/Simulink method is well enough to represent the overall hybrid PV systems by considering measurable code, fast time development and simply integrated with other computational techniques rather than implementing conventional language programming.

The improving efficiency of hybrid photovoltaic-thermal does make sense in terms of electrical and thermal efficiency. With proper design, the electrical efficiency can be further extended as results of 'radiator system' that provides cooling effect on PV module. In fact, the application of hybrid photovoltaic-thermal is not only for the heating demand system but for cooling system as well. Some study results indicate that integrated PV systems is potential to be the 
promising energy source for heating and cooling demand system for household applications in the future [8]. The overall performance can be improved further by combination with other thermal sources, such as combined heat and power (CHP). The technique is implemented to anticipate the temporal distribution of flux radiation of sunlight [9].

This research is focused on the improving mechanism of the fluid flow by implementing the microcontroller ATmega8535 as the pump driver to fluid media once sensor reaches the temperature threshold. For this reason, the back side of photovoltaic module is modified by encapsulating with thermal insulation material and setting piping system in the air cavity between the module and the wall insulation material. The idea is the microcontroller will operate pump to flow the media fluid through designed spiral pipe when the temperature inside the air cavity increases, therefore high temperature fluid can be observed in the outlet pipe. Other supporting components are windshield wisher pumps, temperature sensor of LM35D2 and language programming of Code Vision AVR for the microcontroller utilization. Further control development of hybrid photovoltaic-thermal in this research is oriented for the building integrated photovoltaic (BIPV) systems.

\section{CONFiguration OF PROPOSED SySTEMS}

It is well-known that the photovoltaic systems conventionally produce electrical energy by direct conversion from sun energy. However, the electrical efficiency conversion is not so high because majority portion of sunlight energy on the module surface is reflected and transferred to thermal energy. The increasing in temperature significantly reduces the output power by means further reducing electrical efficiency conversion. Therefore, providing additional system to absorb the thermal effect at the back side of the PV module tends to improve the photovoltaic system performance. Consequently, additional output energy can be observed in the form of thermal energy, therefore improving the overall efficiency conversion of PV system.

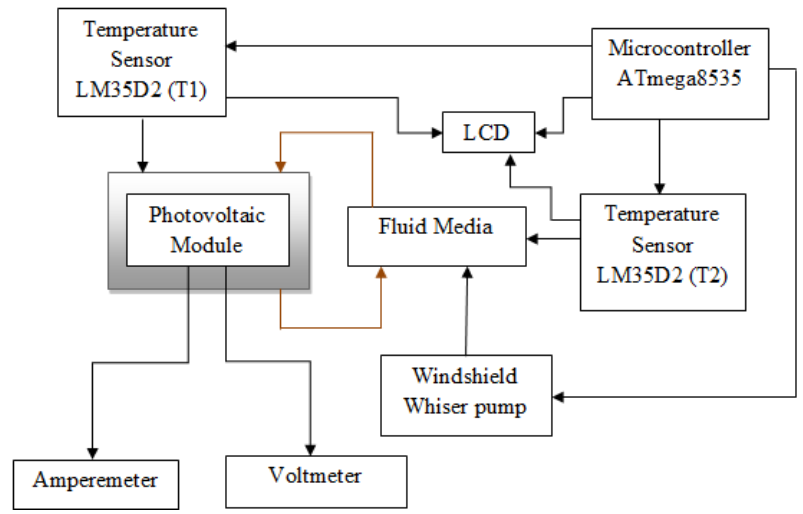

Fig. 1. Proposed control mechanism for hybrid photovoltaic-thermal.

The structure of hybrid photovoltaic-thermal to produce electric and thermal energy simultaneously is not a new thing but the control design is rapidly developed. The main structure is the piping system as the media flow of fluid installed in the bottom parts of module between air cavities under encapsulation of thermal insulation material. The fluid is intentionally flown by means of controlling system once the temperature increases to certain level. For this reason, it is important to design the control in order to guarantee that the thermal energy is successfully extracted. The configuration of control circuit based on the microcontroller ATmega8535 utilization for hybrid photovoltaic-thermal design is shown in Fig. 1.

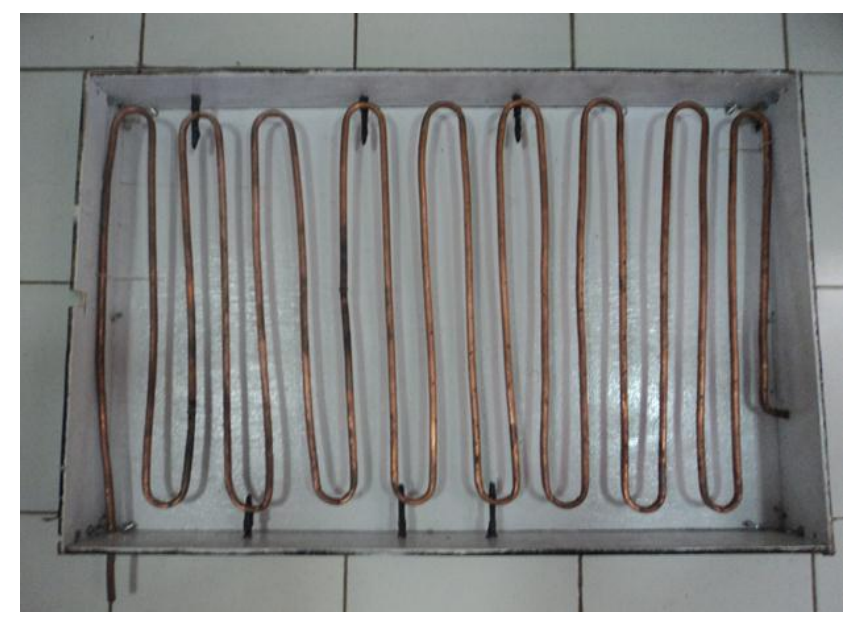

Fig. 2. Construction of spiral copper pipe in the box extraction.

In the schematic configuration, the photovoltaic module is placed over designed box that functions as encapsulation for the thermal energy. The box for the heat has dimension of $85 \times 55 \times 10 \mathrm{~cm}^{3}$ following the size area of photovoltaic module. The purpose to set $10 \mathrm{~cm}$ high for the box is to allow the spiral pipe not touching the any parts of module and box in order to narrowing the space of thermal extraction. Meanwhile, the copper spiral pipe is constructed with 17 indentations by 50 $\mathrm{cm}$ long which is according to wide of box extraction. Indentation is intentionally made to allow high fluid discharge. The copper pipe is spirally arranged inside the box as shown in Fig. 2 that functions as medium of fluid flow. The temperature sensor of LM35D2 (T1) is located inside the box to measure the temperature at back side of PV module. A windshield whiser pump is used to pump the fluid media through the spiraling pipe and fluid storage. Another temperature sensor LM35D2 (T2) is located inside the fluid storage to measure the fluid outlet temperature. Both temperature measurements are then displayed in liquid crystal display (LCD).

In addition, the control circuit which is mainly the microcontroller of ATmega8535 and other electronic components respond following the instruction by designed program written in $\mathrm{C}$ and compiled in Codevision AVR software. The algorithm is very simple which is only based on the temperature threshold set inside the encapsulated box. If this temperature reaches value higher than $45^{\circ} \mathrm{C}$ then microcontroller operates windshield whiser motor to pump the fluid through the spiraling pipe back to the fluid storage. The microcontroller circuit also regulates sensor performance, motor pump and LCD monitor. In order to measure the electrical output power, the voltmeter and amperemeter are connected in the terminal output of PV module.

The physical appearance of photovoltaic module and windshield whiser pump is shown in Fig. 3. The type of photovoltaic module is a multicrystalline Silicon of $50 \mathrm{Wp}$, 
while the windshield whiser pump is similar to the dc motor with IC L293D as pump driver controlled by microcontroller ATmega8535. The technical specification of PV module and windshield whiser pump is presented in Table I, while other supporting components for design of hybrid photovoltaic thermal is shown in Table II.
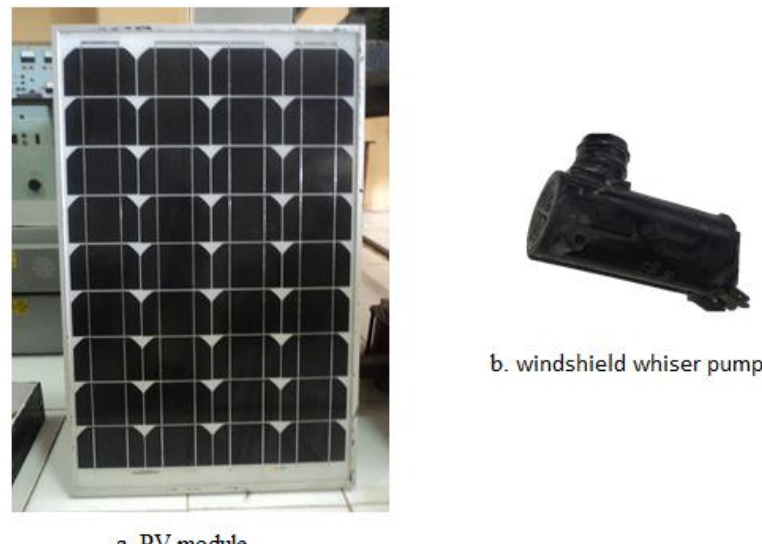

b. windshield whiser pump

module

Fig. 3. Photovoltaic module and windshield whiser pump.

TABLE I: TEChNICAL SPECIFICATION OF PV MODULE AND PUMP

\begin{tabular}{ll|l}
\hline \multicolumn{2}{c|}{ PV Module } & \multicolumn{2}{|l}{ Windshield Whiser Pump } \\
\hline Module Type & $:$ WJ50-M & Brand name : INXT \\
Rate maximum power & $: 50 \mathrm{Wp}$ & Model number : AWP107-10 \\
Tolerance & $: \pm 5 \%$ & Rated voltage $: 12 / 24$ Volt \\
Open circuit voltage (Voc) & $: 21.6 \mathrm{~V}$ & Weight $\quad: 0.065 \mathrm{KG}$ \\
Short circuit current (ISC) & $: 3.01 \mathrm{~A}$ & Color $\quad:$ Black \\
Maximum power voltage $(\mathrm{Vmp})$ & $: 17.6 \mathrm{~V}$ & Material $\quad:$ PA6+30\% GF, ABS \\
Maximum power current (Imp) & $: 2.84 \mathrm{~A}$ & Flow Rate $\quad: 2400 \mathrm{ml} / \mathrm{min}$ \\
Working Temperature & $:-45^{\circ} \mathrm{C}$ to $+35^{\circ} \mathrm{C}$ & Certification $\quad:$ ISO $/ \mathrm{TS} 16949$ \\
Irradiance & $: 1000 \mathrm{~W} / \mathrm{m}^{2}$ & \\
Weight & $: 5 \mathrm{~kg}$ & \\
Dimension & $:(854 \times 541 \times 30) \mathrm{mm}$ & \\
\hline
\end{tabular}

The control circuit is developed according to the AVR microcontroller utilization. In general, the architecture of AVR microcontroller has RISC 8 byte, where all instructions are packaged in 16 byte code and majority of instruction are executed in 1 cycle of clock. Therefore, the time execution for instruction is totally different with MSC51 microcontroller where it requires 12 cycle of clock. The AVR and MSC51 microcontrollers are totally different in terms of architecture where AVR based on RISC (Reduced Instruction Set Computing) technology, while MCS51 based on CISC (Complex Instruction Set Computing) technology. In addition, the AVR microcontroller is divided into four classes of family, i.e ATtiny, AT90Sxx, ATmega and AT86RFxx. Their architecture are basically similar, they are mainly difference in memory, peripheral and function.

In this research, the AVR microcontroller ATmega8535 is utilized. The pin configuration can be seen in Fig. 4. According to this figure, the microcontroller has some important features and capabilities for instance there are 32 of I/O port divided into Port A, Port B, Port C and Port D, 8 byte microprocessor system based on RSIC with maximal speed of $16 \mathrm{MHz} ; 8$ channel of 10 byte internal ADC, 3 timer/counter with comparator capability, 32 registry of CPU, watchdog timer with internal oscillator, SRAM with 512 bytes, flash memory with $8 \mathrm{~Kb}$ with Real While Write capability. They also have internal and external unit interruption, SPI port interface, EEPROM with 512 byte that can be programmed during operation, analog comparator interface and USART port for serial communication with $2.5 \mathrm{MBps}$.

TABLE II: OTHER SUPPORTING COMPONENTS

\begin{tabular}{c|c}
\hline Components & Qty \\
\hline Copper pipe $3 / 8^{\prime \prime}$ & $13 \mathrm{~m}$ \\
\hline Triplex box & 1 \\
\hline Plastic pipe $5 / 8^{\prime \prime}$ & $2.03 \mathrm{~m}$ \\
\hline Resistor $4.7 \Omega$ & 1 \\
\hline Resistor $1 \mathrm{~K}$. & 3 \\
\hline Capacitor $22 \mathrm{pF}$ & 2 \\
\hline Capacitor $100 \mathrm{nF}$ & 3 \\
\hline Capacitor (elco) $1000 \mu \mathrm{F}$ & 1 \\
\hline Diode $2 \mathrm{~A}$ & 1 \\
\hline LED & 1 \\
\hline Regulator 7805 & 2 \\
\hline LCD & 1 \\
\hline L293D & 1 \\
\hline LM35D2 & 2 \\
\hline Xtall & 1 \\
\hline Rainbow cable & $1.5 \mathrm{~m}$ \\
\hline
\end{tabular}

\begin{tabular}{|c|c|c|c|c|}
\hline & & & & \\
\hline (ХCK/TO) PBO $\square$ & 1 & 40 & 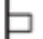 & PAO (ADCO) \\
\hline (T1) PB1 & 2 & 39 & 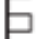 & PA1 (ADC1) \\
\hline (INT2/AINO) PB2 & 3 & 38 & 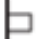 & PA2 (ADC2) \\
\hline (OCO/AIN1) PB3 미 & 4 & 37 & 巨 & PA3 (ADC3) \\
\hline 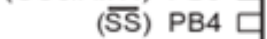 & 5 & 36 & 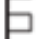 & PA4 (ADC4) \\
\hline (MOSI) PB5 $\square$ & 6 & 35 & 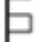 & PA5 (ADC5) \\
\hline (MISO) PB6 무 & 7 & 34 & 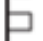 & PA6 (ADC6) \\
\hline (SCK) PB7 무 & 8 & 33 & 曰 & PA7 (ADC7) \\
\hline RESET $\square$ & 9 & 32 & 曰 & AREF \\
\hline VCC $\square$ & 10 & 31 & 口 & GND \\
\hline GND $\square$ & 11 & 30 & 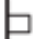 & AVCC \\
\hline XTAL2 무 & 12 & 29 & 巨 & PC7 (TOSC2) \\
\hline XTAL1 며 & 13 & 28 & 口 & PC6 (TOSC1) \\
\hline (RXD) PDO $\square$ & 14 & 27 & 曰 & PC5 \\
\hline (TXD) PD1 $\square$ & 15 & 26 & 曰 & PC4 \\
\hline (INTO) PD2 $\square$ & 16 & 25 & 巨 & $\mathrm{PC}_{3}$ \\
\hline (INT1) PD3 면 & 17 & 24 & 口 & PC2 \\
\hline 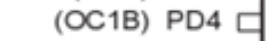 & 18 & 23 & 巨 & PC1 (SDA) \\
\hline (OC1A) PD5 마 & 19 & 22 & 巨 & $\mathrm{PCO}$ (SCL) \\
\hline (ICP1) PD6 문 & 20 & 21 & 巨 & PD7 (OC2) \\
\hline
\end{tabular}

Fig. 4. Configuration of AVR microcontroller ATmega8535.

\section{TESTING DESIGN AND DisCUSSION}

In this experiment, the electrical parameters (voltage and current) and thermal parameter (temperature) are measured simultaneously. The control performance is tested for water fluid under different weather conditions (clear sky, cloudy sky and rain). The data measurement is normally taken from 9 am to $2 \mathrm{pm}$ and the temperature threshold as the reference controller is $45^{\circ} \mathrm{C}$.

In the electrical measurement, the photovoltaic module is connected to the voltmeter and amperemeter in order to measure the output power. The measured power is the output power after the control circuit which is actually composed of linear and non-linear load. The important consideration is the windshield whiser pump that acts as non-linear load. When 
the pump is activated, it will effect to the decrease in voltage and increase in current. However, the deviation of this value is still in the tolerable level; therefore the overall system functions. Meanwhile, only the temperature difference between the box extraction and fluid storage is considered in the thermal power measurement.

The efficiency calculation is based on the ratio between output power and input power. The electrical efficiency $\left(\eta_{e}\right)$ of PV module is about $10.69 \%$ following the calculation:

$$
\eta_{e}=\frac{P_{\text {output }}(\max )}{P_{\text {input }}(\max )} \times 100 \%
$$

where $P_{\text {output }}(\max )$ is the maximum available output power for PV module $(50 \mathrm{~W})$ and $P_{\text {input }}(\max )$ is multiplication between the maximum global irradiance $\left(1000 \mathrm{~W} / \mathrm{m}^{2}\right)$ and surface area of PV module $\left(0.4675 \mathrm{~m}^{2}\right)$; therefore $P_{\text {input }}(\max )=467.5 \mathrm{~W}$. Nevertheless, the electrical power output measurement is simply calculated as:

$$
P_{\text {out } 1}=V \times I
$$

where $V$ and $I$ are the voltage and current measurements, respectively.

For the thermal efficiency calculation, the heat energy of fluid is determined by:

$$
\Delta Q=m c\left(T_{2}-T_{1}\right)
$$

where the mass $(m)$ of water is $15 \mathrm{~kg}$ and specific heat capacity ( $c$ ) of water is $4200 \mathrm{~J} / \mathrm{kg}^{\circ} \mathrm{C}$. The temperature $T_{2}$ and $T_{1}$ are the thermal sensor measurement. If 1 Joule is equivalent to 1 joule $=2.7778 \times 10^{-4} \mathrm{Wh}$, the thermal power in Wh can be calculated as follows:

$$
P_{\text {out } 2}=\frac{Q \times 2.77 \times 10^{-4}}{t}
$$

where $t$ is the time measurement between 9 am and 2 pm (5 hours).

Finally, the total efficiency for hybrid photovoltaic thermal is calculated by:

$$
\eta_{\text {tot }}=\frac{P_{\text {out } 1}+P_{\text {out } 2}}{P_{\text {in }}} \times 100 \%
$$

Table III shows the testing results of controller performance using water as the media fluid. There are three different sky conditions for the measurement, i.e. clear, cloudy and rainy. In the electrical output, current and voltage measurement are influenced by the operation of windshield whiser pump. During the pump operation, the load of control circuit becomes non-linear, while it is linear when the pump is off. Under clear sky measurement, the efficiency starts increasing to $12.801 \%$ at 10.30 am and continuing to $22.06 \%$ at the end of experimental works $(2 \mathrm{pm})$. It means that the much higher efficiency may be expected at the late of afternoon where the hot water is needed for households.
Under cloudy sky operation, the increasing output is little late and also the final efficiency system is lower than that of clear sky operation result. The efficiency is getting worst under rainy operation where the intensity of sunlight is low. However, the control system is response fast once the rainy stops and the PV panel receiving sunlight at $1 \mathrm{pm}$.

Our proposed control system for hybrid photovoltaic thermal is designed for small scale PV system. However, it is also suitable for high capacity installation of PV system. To do so, it is important to modify the hardware and software of the current design system. The hardware components that need to be modify is heat box extraction, dimension of pipe and fluid storage. For instance, with $10 \mathrm{PV}$ modules in series, the dimension of heat box extraction will be $850 \times 55 \times 10 \mathrm{~cm}^{3}$, consequently affecting the dimension of pipe and increasing the fluid volume in fluid storage. In terms of software modification, it is highly depending on the type of motor pump. The utilization of AC motor is possible, however additional inverter system must be added since the powering of motor is coming from PV module output; therefore the wiring system is getting much more complex.

Improving control system for the hybrid photovoltaic thermal is one of the ways to enhance the performance of system and to increase the efficiency. Our experimental design is very simple therefore the efficiency is not so high but it still may open to be increased. The part that is important to be improved is the material and thermal insulation of the heat box extraction. Instead of using wood and plastic for the box extraction, the Aluminum, galvanized steel plate with using polyurethane and fibre-glass wool can be recommended to keep the heat much longer in time. Adding heat storage components will be also very useful for the thermal utilization at night. If our proposed design system comes up with very sophisticated components and materials, the expected efficiency may reach above $60 \%$. However, getting complex technical system will be consequent to increase the overall cost of the system.

\section{CONCLUSIONS}

The paper has explained the control mechanism in hybrid photovoltaic thermal using microcontroller ATmega8535. Two thermal sensors are utilized in this experimental works. The first thermal sensor of LM35D2 is located inside the thermal box extraction to measure the temperature at back side of PV module as the heat source. Another thermal sensor of LM35D2 is located inside the fluid storage to measure the fluid outlet temperature. If the temperature inside the box extraction reaches value higher than $45^{\circ} \mathrm{C}$ then microcontroller operates windshield whiser motor to pump the fluid through the spiraling pipe back to the fluid storage. The control process stops once the temperatures between two thermal sensors are equal. Several testing on water fluid under clear sky, cloudy sky and rainy condition are conducted in order to confirm the proper working condition of controller. The advantage of this system is the simple algorithm with high potential of efficiency improvement by implementing sophisticated materials and components and may be useful for high capacity of PV installation. 
TABLE III: MEASUREMENT RESULTS FOR WATER AS THE MEDIA FLUID

\begin{tabular}{|c|c|c|c|c|c|c|c|c|c|c|}
\hline Time & $\mathrm{V}(\mathrm{V})$ & $\mathrm{I}(\mathrm{A})$ & $\mathrm{T} 1 \quad\left({ }^{\circ} \mathrm{C}\right)$ & $\mathrm{T} 2\left({ }^{\circ} \mathrm{C}\right)$ & $\Delta \mathrm{T}\left({ }^{\circ} \mathrm{C}\right)$ & Q (Joule) & $\mathrm{P}_{\text {out } 1}(\mathrm{~W})$ & $\mathrm{P}_{\text {out2 }}(\mathrm{W})$ & $\mathrm{P}_{\text {in }}(\mathrm{W})$ & $\eta_{\text {Total }}(\%)$ \\
\hline \multicolumn{11}{|c|}{ Clear sky measurement, Monday 11 February 2015} \\
\hline 09.00 & 18.98 & 0.065 & 43 & 31 & 0 & 0 & 1.23 & 0 & 12.337 & 10 \\
\hline 09.30 & 18.67 & 0.065 & 43 & 31 & 1 & 63000 & 1.21 & 0 & 12.135 & 10 \\
\hline 10.00 & 18.57 & 0.065 & 44 & 31 & 2 & 126000 & 1.2 & 0 & 12.07 & 10 \\
\hline 10.30 & 13.88 & 2.7 & 45 & 34 & 3 & 18900 & 37.48 & 10.5 & 374.76 & 12.801 \\
\hline 11.00 & 14.08 & 2.8 & 46 & 36 & 5 & 315000 & 39.42 & 17.5 & 394.24 & 14.43 \\
\hline 11.30 & 14.02 & 2.8 & 48 & 38 & 7 & 441000 & 39.26 & 24.5 & 392.56 & 16.24 \\
\hline 12.00 & 14.2 & 2.8 & 49 & 38 & 7 & 441000 & 39.76 & 24.5 & 397.6 & 16.16 \\
\hline 12.30 & 14.06 & 2.8 & 50 & 39 & 8 & 504000 & 39.37 & 28 & 393.68 & 17.11 \\
\hline 13.00 & 14.06 & 2.8 & 50 & 40 & 9 & 567000 & 39.37 & 31.5 & 393.68 & 18 \\
\hline 13.30 & 13.66 & 2.7 & 52 & 41 & 10 & 630000 & 36.88 & 35 & 368.82 & 19.48 \\
\hline 14.00 & 13.97 & 2.7 & 52 & 44 & 13 & 819000 & 37.72 & 45.5 & 377.19 & 22.06 \\
\hline \multicolumn{11}{|c|}{ Cloudy sky measurement, Saturday 16 February 2015} \\
\hline 09.00 & 18.92 & 0.065 & 36 & 31 & 0 & 0 & 1.22 & 0 & 12.29 & 10 \\
\hline 09.30 & 18.7 & 0.065 & 38 & 31 & 0 & 0 & 1.21 & 0 & 12.15 & 10 \\
\hline 10.00 & 18.67 & 0.065 & 40 & 31 & 0 & 0 & 1.21 & 0 & 1213 & 10 \\
\hline 10.30 & 18.45 & 0.065 & 41 & 31 & 0 & 0 & 1.19 & 0 & 11.99 & 10 \\
\hline 11.00 & 18.68 & 0.065 & 44 & 31 & 0 & 0 & 1.21 & 0 & 12.14 & 10 \\
\hline 11.30 & 12.01 & 2.5 & 46 & 33 & 2 & 126000 & 30.02 & 7 & 300.25 & 12.33 \\
\hline 12.00 & 12.54 & 2.7 & 47 & 34 & 3 & 189000 & 33.85 & 10.5 & 338.58 & 13.10 \\
\hline 12.30 & 12.47 & 2.7 & 48 & 34 & 3 & 189000 & 33.67 & 10.5 & 336.69 & 13.11 \\
\hline 13.00 & 12.38 & 2.7 & 48 & 35 & 4 & 252000 & 33.42 & 14 & 334.26 & 14.18 \\
\hline 13.30 & 12.11 & 2.6 & 47 & 36 & 5 & 315000 & 31.5 & 17.5 & 314.86 & 15.55 \\
\hline 14.00 & 12.29 & 2.7 & 48 & 37 & 6 & 378000 & 33.18 & 21 & 331.83 & 16.32 \\
\hline \multicolumn{11}{|c|}{ Rainy measurement, Tuesday 19 February 2015} \\
\hline 09.00 & 18.2 & 0.065 & 32 & 31 & 0 & 0 & 1.18 & 0 & 11.83 & 10 \\
\hline 09.30 & 18.37 & 0.065 & 32 & 31 & 0 & 0 & 1.19 & 0 & 11.94 & 10 \\
\hline 10.00 & 18.15 & 0.065 & 32 & 31 & 0 & 0 & 1.17 & 0 & 11.79 & 10 \\
\hline 10.30 & 17.89 & 0.065 & 32 & 31 & 0 & 0 & 1.16 & 0 & 11.62 & 10 \\
\hline 11.00 & 18.57 & 0.065 & 33 & 31 & 0 & 0 & 1.2 & 0 & 12.07 & 10 \\
\hline 11.30 & 18.53 & 0.065 & 36 & 31 & 0 & 0 & 1.2 & 0 & 12.04 & 10 \\
\hline 12.00 & 18.63 & 0.065 & 38 & 31 & 0 & 0 & 1.21 & 0 & 12.10 & 10 \\
\hline 12.30 & 18.72 & 0.065 & 41 & 31 & 0 & 0 & 1.21 & 0 & 12.16 & 10 \\
\hline 13.00 & 18.81 & 0.065 & 44 & 31 & 0 & 0 & 1.22 & 0 & 12.22 & 10 \\
\hline 13.30 & 11.76 & 2.5 & 45 & 33 & 2 & 126000 & 29.4 & 7 & 294 & 12.38 \\
\hline 14.00 & 12.05 & 2.5 & 45 & 34 & 3 & 189000 & 30.12 & 10.5 & 301.25 & 13.48 \\
\hline
\end{tabular}

\section{REFERENCES}

[1] Chow, "A review on photovoltaic/thermal hybrid solar technology," Applied Energy, vol. 87, no. 2, pp. 365-379, 2010.

[2] Nagano et al., "Development of thermal-photovoltaic hybrid exterior wallboards incorporating PV cells in and their winter performances," Solar Energy Materials and Solar Cells, vol. 77, no. 3, pp. 265-282, 2003.

[3] Anand and Tiwari, "Energy and exergy efficiencies of a hybrid photovoltaic-thermal (PV/T) air collector," Renewable Energy, vol. 32 no. 13, pp. 2223-2241, 2007.

[4] Agarwal and Tiwari, "Energy and exergy analysis of hybrid micro-channel photovoltaic thermal module," Solar Energy, vol. 85, no. 2, pp. 356-370, 2011.

[5] Jie, et al., "Effect of fluid flow and packing factor on energy performance of a wall-mounted hybrid photovoltaic/water-heating collector system," Energy and Buildings, vol. 38, no. 12, pp. 1380-1387, 2006.

[6] Jie, et al., "A sensitivity study of a hybrid photovoltaic/thermal water-heating system with natural circulation," Applied Energy, vol. 84 , no. 2, pp. 222-237, 2007.

[7] da Silva and Fernandez, "Hybrid photovoltaic/thermal (PV/T) solar systems simulation with Simulink/Matlab," Solar Energy, vol. 84, no. 12, pp. 1985-1996, 2010.
[8] Vokas, et al., "Hybrid photovoltaic-thermal systems for domestic heating and cooling - A theoretical approach," Solar Energy, vol. 80, no. 5, pp. 607-615, 2006.

[9] Pearce, "Expanding photovoltaic penetration with residential distributed generation from hybrid solar photovoltaic and combined heat and power systems," Energy, vol. 34, no. 11, pp. 1947-1954, 2009.

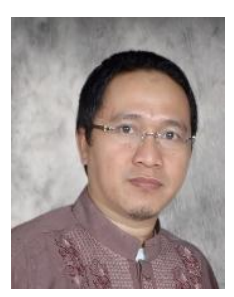

Syafaruddin received his B.Eng degree in electrical engineering from Universitas Hasanuddin, Indonesia, in 1996, M.Eng degree in electrical engineering from University of Queensland, Australia, in 2004 and D.Eng degree from Kumamoto University, Japan in 2009. He has been working in Kumamoto University for two years as a project assistant professor for Graduate School of Science and Technology, sponsored by Endowed Chair of Kumamoto University. His current position is a senior lecturer in the Department of Electrical Engineering, Universitas Hasanuddin, Indonesia. His research interests include renewable energy integration and optimization, maximum power point tracking control of photovoltaic system, real-time system and intelligent system applications to power system. 


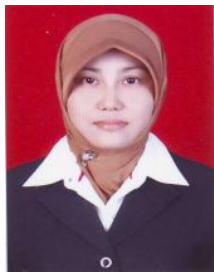

Satriani Latief graduated with her B.Eng degree in the field of architecture from Universitas Muslim, Indonesia in 1999, master degree in the field architecture from Universitas Hasanuddin in 2010. Her research interests include building design for urban planning especially for the renewable energy building utilization. Recently, she is working in Universitas Bosowa Indonesia in the Department of Architecture and she is actively in several urban and

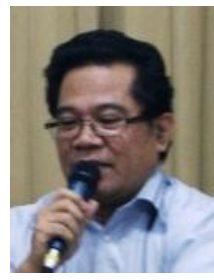

Wahyu H. Piarah graduated with his doctoral degree from TU Berlin in 2001 in the field of process engineering taken the energy conversion as minor project. His research areas include mass fluid transfer and energy conversion. Currently, he is working in the Department of Mechanical Engineering, Universitas Hasanuddin. He is also the dean of the Faculty of Engineering of Universitas Hasanuddin. rural area development in Indonesia. 